\title{
LAJANG DALAM GEREJA DAN PELAYANAN
}

\author{
Mariani Febriana
}

\section{ABSTRAKSI}

Berbagai macam stereotip dan stigma yang diberikan kepada para lajang dalam kehidupan sehari-sehari. Tidak tertutup kemungkinan penilaian itu juga terjadi di dalam gereja Tuhan. Beranjak dari pemikiran Yesus dan Paulus, maka melajang atau menikah bukanlah suatu persoalan utamanya. Melainkan persoalan penting hari ini adalah apakah dalam budaya yang berorientasi kepada keluarga hari ini, para lajang mendapatkan penghargaan dan penerimaan yang berimbang dari gereja terhadap diri mereka. Penerimaan berimbang di sini diperhadapkan dengan komparasi cara gereja bersikap terhadap mereka yang sudah menikah dan kepada para lajang di dalam pelayanan dalam suatu kategori tertentu yang menampakkan suatu pembedaan yang signifikan.

Sikap pembedaan ini tidak boleh tumbuh subur dalam gereja, karena Kitab Suci membuka kesempatan bagi kedua itu ada dalam gereja, khususnya dalam melayani Allah. Karena itu, harus ada suatu perubahan paradigma cara berpikir gereja terhadap para lajang untuk menuju kepada suatu komunitas gereja yang transformatif. Perayaan gereja dalam pelayanannya diletakkan kepada identitas mereka dalam Kristus dan bukan karena status melajang atau menikah atau apapun yang gereja hendak kenakan pada dirinya.

Lajang dalam pelayanan gereja adalah suatu karunia dalam hidup gereja dan karena itu gereja harus mendukung dan mendorong mereka untuk melakukan suatu karya pelayanan yang lebih besar, agar pertumbuhan dari tubuh Kristus mencapai tujuan yang dikehendaki oleh Allah.

\footnotetext{
Kata kunci: Lajang, Menikah, Pelayanan, Kultur Masyarakat, Sikap Gereja.
} 


\section{PENDAHULUAN}

Majalah Bahana dalam edisi Agustus 2009 memaparkan suatu tema yang sangat unik dengan judul Lajang bukan yang Terbuang. Lajang dalam hal ini memang didefinisikan dalam berbagai macam arti, yaitu yang sedang menantikan masa pernikahan, lajang karena perceraian akibat kematian dan lajang yang memang tidak pernah menikah. Dalam artikel ini menyoroti soal lajang yang memang tidak pernah menikah dan mengambil keputusan untuk tidak menikah karena alasan tertentu.

Artikel ini menjelaskan bahwa menjadi lajang dalam pengertian tidak pernah menikah dan mengambil keputusan melajang dalam masyarakat yang berkultur tradisional bukanlah suatu hal yang mudah. Ada berbagai macam stigma negatif yang diberikan berkaitan dengan kondisi ini, yaitu diantaranya orang sulit, tak laku, memiliki hambatan psikologis, suka memilih dan bahkan pandangan yang ekstrim diberikan juga, yaitu adanya disorientasi seksual. Karena itu kelajangan dalam masyarakat tradisional seperti ini dianggap sebagai suatu hal yang tidak wajar ${ }^{1}$ dan sekaligus dianggap sebagai pribadi yang menyimpang secara sosial. $^{2}$ Harapan budaya secara umum tentang pernikahan dengan segala keanekaragamannya diterjemahkan ke dalam berbagai macam prasangka terhadap para lajang. Sebagai contoh, jikalau pernikahan adalah suatu tanda kedewasaan, penghormatan dan sukses, maka menjadi lajang itu berarti suatu tanda ketidakdewasaan, kesembronoan dan suatu kegagalan. ${ }^{3}$

Di sisi lain, dalam konteks tertentu ada yang sangat meninggikan kelajangan seolah-olah panggilan kelajangan lebih tinggi dan lebih suci daripada menikah. Secara khusus dalam tradisi asketis yang merendahkan seksualitas sebagai suatu hawa nafsu yang dilegalkan. Padahal sesungguhnya seks itu adalah

\footnotetext{
1 Krisetiawati Puspitasari, "Lajang Bukan yang Terbuang, Bahana, Agustus 2009, diakses dari http://www.ebahana.com/warta-1156-LAJANG-BUKAN-YANGTERBUANG.html, tanggal 13 Februari 2015.

2 Anne Byrne, "Single Women in Ireland," Women on Their Own: Interdisciplinary Perspective on Being Single, ed. by Rudolf M. Bell and Virginia Yans (London:

Rutgers University Press, 2008), 22.

3 Sylvia Creswell, Singleness and the Church, diakses dari

file://G:/Singleness\%20and\%20the\%20Church\%20Sylvia\%20Cresswell.pdf, tanggal 15 Februari 2015
} 
pemberian Allah yang baik dan pernikahan juga ada dalam institusi Allah. ${ }^{4}$ Jadi dalam hal ini, jikalau pernikahan itu baik, maka demikian juga dengan kondisi lajang.

Persoalan yang justru timbul saat ini di mana angka kelajangan meningkat khususnya di kota-kota besar justru tidak mendapat tanggapan serius dari gereja. Di dalam hidup gereja yang sangat berorientasi kepada hidup keluarga menyebabkan banyak para lajang yang tidak mendapat perhatian dan pelayanan khusus. Gereja sangat serius memperhatikan mereka yang sudah menikah, namun mengabaikan perhatiannya kepada para lajang. ${ }^{5}$ Lebih lanjut perlakuan yang berbeda kepada para lajang, khususnya para pelayan yang lajang dalam gereja seringkali menyebabkan situasi yang tidak menyenangkan. Secara emosional pun mereka juga mengalami kondisi isolasi emosional dan seringkali tindakannya bisa dicurigai, manakala seorang lajang perempuan yang adalah seorang pelayan dalam gereja melaksanakan tindakan pelayanan-pelayanan tertentu. Akibatnya, depresi dan kesepian menjadi wabah bagi para lajang di tengah komunitas beriman. ${ }^{6}$

Gereja adalah suatu komunitas beriman yang di dalamnya para lajang juga melayani dan beribadah dan karena itu hendaknya gereja mempromosikan program dan persekutuan serta pola-pola relasi yang inkulusif juga bagi para lajang. ${ }^{7}$ Gereja dalam hal ini dapat mengembangkan suatu tindakan yang lebih sensitif terhadap para lajang dengan membangun suatu komunitas beriman yang menerima, menumbuhkan, mengasihi dan mendukung, sebagai suatu keluarga Allah yang sejati dimana semua orang diterima, dikasihi dan didukung secara berimbang.

\footnotetext{
${ }^{4}$ Wawancara Albert Hsu dan John Stott dalam Albert Hsu, Singles at the Crossroads: A Fresh Perspective on Christian Singleness (Downers Grove, IVP Books, 1997), 177.

5 William Lyon, A Pew for One, Please: The Church and the Single Person (New York: Cross Road Book, 1977), 5.

6 Clyde Ervine, Single in the Church: Eunuchs in the Kingdom, p. diakses dari www.biblicalstudies.org.uk/pdf/churchman/119-03_217.pdf, tanggal 13 Februari 2015.

7 lbid., 218.
} 


\section{MENIKAH ATAU TIDAK MENIKAH ADALAH SUATU KEADAAN YANG BERIMBANG DALAM KITAB SUCI: SUATU RESPONS TERHADAP KETIDAKNYAMANAN SIKAP GEREJA TERHADAP PARA LAJANG}

Ketidaknyamanan sikap gereja terhadap para lajang dipicu oleh suatu praanggapan yang salah bahwa menikah itu adalah suatu keharusan karena dikatakan tidak baik kalau manusia itu seorang diri saja. Menikah juga dianggap sebagai suatu pemenuhan tanggung jawab moral terhadap perintah ilahi untuk beranak cucu dan bertambah banyak. Karena itu, dalam pemikiran Yahudi, pernikahan adalah suatu kewajiban moral yang absolut dan sebagai suatu panggilan hidup yang tertinggi, serta sebagai suatu kewajiban moral.

Pemikiran itulah yang ditantang oleh Yesus, yang menganggap bahwa panggilan menikah adalah panggilan terhormat bila dibandingkan dengan menjadi lajang (Matius 19:12). Dalam konteks komunitas Yahudi, tidak menikah dianggap sebagai orang yang cacat dan tidak pas secara sosial. Bahkan sikap ini menyebar dalam beberapa kultur masyarakat di dunia. Bahkan hari ini juga ada suatu stigma yang diberikan kepada para lajang, " singlism," yaitu suatu istilah yang digunakan oleh Profesor psikologi sosial Bella De Paulo untuk menggambarkan prasangka terhadap para lajang yang tidak masuk dalam suatu komitmen relasi. $^{8}$

Jawaban Yesus terhadap pertanyaan para Farisi yang sangat provokatif mengenai perceraian memberikan pemahaman baru bahwa hidup lajang ataupun menikah merupakan suatu anugerah Allah, terlepas dari alasan-alasan yang bersifat keakuan diri. Jawaban Yesus membuka suatu babak baru dalam kehidupan bahwa sebenarnya pernikahan bukanlah suatu keharusan dalam kehidupan dan hidup lajang bukanlah suatu hal yang memalukan dan yang perlu dikasihani. Masing-masing harus dihargai dalam konteks di mana keputusan itu diambil dalam terang kerajaan Allah. Stanley Grenz memberikan gambaran unik tentang Allah,

${ }^{8}$ Charlotte Metcalf, Stigmatised for being single: More women are choosing to live alone but they're becoming irritated at being pitied and patronised by their married friends, diakses dari http://www.dailymail.co.uk/femail/article2070914/Stigmatised-single-More-women-choosing-live-alone.html, tgl 13 Februari 2015. 
entah itu dalam kehidupan dalam pernikahan dan menjadi lajang. Grenz menyebutkan bahwa sama seperti hidup dalam pernikahan memberikan tanda tentang siapa Allah itu,maka demikian juga dalam kehidupan para lajang memberikan tanda tentang realitas ilahi yang lain. Grenz mengatakan:

Singleness...constitutes an equally powerful imagery of yet another dimension of the divine reality as the One who loves, namely, the universal, non exclusive, and expanding nature of the divine love...The 'family' formed by the love of single persons is not the product of the intimate sexual acts shared by two people, but arises spontaneously out of a dynamic of love that is open beyond exclusive boundaries. As such, the less formal bonding of singles reflects the openness of the divine love to the continual expansion of the circle of love to include within its circle those yet outside its boundaries. In short, the single life can express the divine reality as characterized by a love that seeks relationship (community) nonexclusively ${ }^{9}$

Dalam tradisi Protestan, karena reaksinya yang sangat keras terhadap selibasi dalam Gereja Katholik, hidup pernikahan itu sangat ditinggikan. Dalam hal ini dicatat bahwa tidak seorangpun yang begitu meninggikan pernikahan dalam sejarah gereja seperti yang sudah dilakukan oleh Luther. ${ }^{10}$ Luther mengatakan,

God has done marriage the honor of putting it into the Fourth Commandment,immediately after the honor due to Him, and commands, "Thou shalt honor father and mother ". Show me an honor in heaven or on earth apart from the honor of God, that can equal this honor! Neither the secular nor the spiritual estate has been so highly honored. And if God had given utterance to nothing more than this Fourth Commandment with reference to married life, men ought to have learned quite well from this Commandment that in God's sight there is no higher office, estate, condition and

\footnotetext{
9 Stanley J Grenz, Sexual Ethics: An Evangelical Perspective (Louisville: John Knox Press, 1990), 195.

${ }^{10}$ Mark Almlie, Are We Afraid of Single Pastors? Diakses dari http://www.christianitytoday.com/parse/2011/january/are-we-afraid-of-singlepastors.html, tanggal 15 Februari 2015.
} 
work next to the Gospel which concerns God Himself) than the estate of marriage. ${ }^{11}$

Luther mengeluarkan pernyataan sedemikian di tengah konteks Abad Pertengahan yang memang menganggap rendah pernikahan dan memandang tinggi hidup dalam kelajangan/selibasi. Hari ini kelompok Injili justru melakukan hal yang berlawanan atau berbalikan dari sikap Abad Pertengahan di mana kelompok Injili menganggap rendah kelajangan dan menekankan berlebihan pada sisi pernikahan. Hsu mengamati bahwa penekanan modern hari ini pada keluarga inti merupakan suatu perkembangan dari individualisme Barat dan budaya industrialisasi abad ke-19 dan hal ini justru bukan mengikuti pola Kitab Suci yang mencakup relasi yang diperluas. ${ }^{12}$ Sejarah mencatat bahwa sangat sulit bagi orang percaya untuk memikirkan pernikahan dan kelajangan secara bersamaan adalah baik. Sedangkan Kitab Suci memberikan isyarat kepada kita untuk melakukan demikian.

Menariknya, sekalipun Kitab Suci membuka pintu bagi kehidupan lajang, namun ada banyak mereka dalam tradisi Protestan justru tidak membuka pintu yang seimbang bagi para lajang. Bahkan seorang ethisist menyebutkan untuk mengkritisi sikap Protestan bahwa keadaan yang tidak menikah itu dalam banyak pemikiran orang Protestan dianggap sebagai suatu kondisi tidak sehat dan suatu penyimpangan dari yang normal. Akibatnya sikap yang diberikan oleh Yesus dan PB khususnya dalam I Korintus 7 justru hilang dalam tradisi Katolik dan Protestan, karena masing-masing meninggikan satu sisi dari sikap yang diberikan oleh Yesus. Bahkan didukung pula dalam Era Reformasi sangat menekankan cara hidup kristen yang utama adalah pernikahan dan keluarga. ${ }^{13}$ Karena itu sikap ini sudah menjadi cikal bakal untuk membentuk banyak pemikiran gereja Protestan dan sikap mereka yang sedikit apriori terhadap para lajang. Akibatnya para lajang terasing dalam hidup gereja.

\footnotetext{
11 Hugh Thomson Kerr, A Compend of Luther's Theology: Martin Luther on Marriage and Divorce, diakses dari

http://www.teleiosministries.com/pdfs/Marriage_Divorce/martin_luther_on_marria ge_and_divorce.pdf, tanggal 16 Februari 2015.

12 Hsu, Single at the Crossroads, 45.

${ }^{13}$ Clyde Ervine, Single in the Church, 223.

${ }^{14} \mathrm{Hsu}$, Single at the Crossroads, 44.
} 
Pemikiran ini terus merambah masuk ke dalam dunia pelayanan gereja. Seharusnya tidak ada perbedaan yang tajam di antara seorang pelayan yang lajang dan yang menikah berkaitan dengan melayani di suatu gereja. Di samping stigma budaya, di sisi lain pemahaman teologis justru semakin memengaruhi sikap dan cara pandang gereja terhadap para lajang. Sekalipun seharusnya sikap gereja berimbang demikian, namun tidaklah demikian dalam dunia nyata, sebagaimana disinyalir oleh Trull dan Carter. ${ }^{15}$ Banyak gereja sedikit ragu memanggil para lajang dalam pelayanan karena ada banyak pertanyaan yang bisa timbul, di antaranya mengapa tidak menikah atau adanya kecurigaan dari para pasangan nikah terhadap para pelayanan yang dilakukan oleh mereka yang tidak menikah jikalau pasangannya berkonsultasi. Di sisi lain, orang tua juga merasa kuatir untuk mempercayakan anak-anak mereka kepada rohaniwan yang tidak menikah.

Pengamatan Carter dan Trull pun dapat tidak berlaku di beberapa tempat tertentu karena justru gereja lebih suka dan cenderung mengambil pelayan yang lajang guna alasan yang sangat praktis yaitu menghemat pengeluaran gereja. Pengamatan Carter dan Trull dalam hal pengeluaran uang gereja untuk para lajang menjadi suatu hal yang menarik untuk dipikirkan. Carter dan Trull mengatakan bahwa gereja seharusnya tidak mengharapkan seorang pelayan yang lajang menghabiskan waktu lebih banyak dalam pelayanan hanya karena alasan mereka lajang.

Gereja seharusnya memanggil orang dalam pelayanan berdasarkan dedikasi mereka kepada Kristus dan kemampuan untuk melakukan tugas yang dimaksud. Bahkan gereja seharusnya tidak memberikan tunjangan kepada para lajang lebih sedikit hanya karena mereka lajang dan tidak mempunyai keluarga untuk mereka dukung, sementara mereka melakukan tugas yang pelayanan yang sama dengan para pelayan yang sudah menikah. Apalagi dalam budaya tertentu suatu kondisi menjadi semakin sulit karena bukan hanya statusnya lajang, melainkan juga karena dia adalah seorang perempuan.

15 Joe E. Trull dan James E. Carter, Ministerial Ethics (Grand Rapids: Baker Book, 2004), 73. 
Sikap pembedaan ini menjadi semakin menonjol dan perlu diwaspadai dalam sistem budaya patriakhat yang menghargai lakilaki lebih daripada perempuan dan melihat pernikahan lebih tinggi daripada hidup lajang. Dalam konteks Asia, khususnya dalam budaya-budaya patriakhat, maka perbedaan ini akan semakin menonjol. Sebagai contoh, pembaharuan besar dalam budaya dan kultur Tiongkok pada hari ini menuju kepada suatu persamaan dalam perlakukan terhadap laki-laki dan perempuan merupakan suatu kemajuan besar pada hari ini.

Selama berabad-abad, Tiongkok memperlakukan sistem pembedaan yang ketat kepada perempuan. Berbagai upaya advokasi dilakukan untuk persamaan hak dan pada hari ini ada suatu kemajuan yang pesat dalam persamaan di antara laki-laki dan perempuan dan tanpa kecuali akan meluas juga kepada sikap kepada para lajang. Ada suatu adagium khusus dalam kultur lama Tiongkok, yang disebut sebagai saat yang membahagiakan yaitu, sukses, menikah dan memiliki anak laki-laki. ${ }^{16}$ Artinya menikah dianggap sebagai suatu hal yang sangat dinantikan dan karena itu dijunjung tinggi. Gereja jikalau tidak mewaspadai hal ini justru akan tenggelam ke dalam kultur budaya yang notabene perlu ditransformasi oleh pemahaman akan Injil Yesus Kristus. Artinya kultur dan budaya tidaklah menjadi prima facie dalam mengatur hidup gereja melainkan Kitab Sucilah yang menuntun bagaimana seharusnya gereja hidup dan melakukan tugas panggilannya.

Trull dan Carter menyoroti perbedaan dan cara sikap gereja yang sangat ambigu ini berdasarkan penilaian yang tidak berimbang dalam perlakuan gereja terhadap pelayan yang menikah atau yang lajang. Sikap gereja yang tidak nyaman terhadap para lajang entah itu dalam bentuk program pelayanan yang sangat berorientasi kepada keluarga dan sikap gereja yang tidak berimbang kepada para pelayannya berkaitan dengan dukungan gereja terhadap para pelayannya hanya karena menikah atau lajang akan menjadikan suatu kesulitan tersendiri dalam pelayanan gereja berhadapan dengan kondisi yang dihadapi para hari ini. Hsu menegaskan bahwa kasih obsesif kelompok Injili dengan keluarga inti ini sudah meninggalkan para

\footnotetext{
16 Dominique G, Chinese Women's Life, diakses dari http://chinesewomenslife.blogspot.com/2010/10/traditional-role-of-women-inchina.html, tanggal 13 Februari 2015.
} 
lajang dalam isolasi yang menyakitkan. ${ }^{17}$ Akibatnya banyak para lajang meninggalkan gereja. Kepergian para lajang dari gereja menyebabkan juga potensi besar dari gereja untuk bertumbuh menjadi berkurang karena bisa jadi mereka yang pergi adalah mereka yang dapat memberikan kontribusi penting dalam pengembangan pelayanan gereja.

\section{SIKAP TRANSFORMATIF GEREJA TERHADAP PARA LAJANG}

Kembali kepada apa yang diajarkan Kitab Suci kepada gereja maka sangat penting di sini untuk dapat memikirkan kembali apa yang dapat dilakukan gereja kepada para lajang. Pelayanan seharusnya diarahkan kepada menemukan kebutuhan sejati dari mereka yang dilayani. Dalam hal ini maka para lajang seharusnya didorong untuk membangun nilai-nilai dan gaya hidup yang seharusnya. Sebagaimana gereja mengajarkan kemitraan dalam pernikahan, maka para lajang pun didorong juga untuk membangun kemitraan bersama dengan sesama. ${ }^{18}$

Memang lamanya melajang membuka suatu gaya tersendiri bagi para lajang yang harus diwaspadai yaitu tidak mau bekerja sama dengan orang lain karena terlalu mandiri dan hidup sendiri dan tidak mau tunduk. Karena selalu memutuskan dengan "saya" dan bukan "kita", maka bahayanya para lajang menjadi sangat sentripetal dan menjadi semakin egois. ${ }^{19}$ Gaya dan cara hidup seperti ini jikalau tidak diwaspadai justru akan menghancurkan kehidupan para lajang, karena sikap seperti ini akan mengarah kepada kesepian, frustrasi dan bahkan isolasi diri. Karena itu adanya program pelayanan gereja yang bersifat inklusif dan bukan hanya "family oriented" akan menolong para lajang dalam mengaktualisasikan dirinya dalam komunitas beriman.

Ervine menyarankan kepada Gereja untuk perlu mengembangkan pemahaman terus menerus bahwa apakah lajang atau menikah sama-sama menjadi milik dari kerajaan Allah. Identitas utama orang percaya bukan soal menikah atau lajang melainkan ciptaan baru dalam Kristus. Identitas orang percaya juga bukan karena dia putih, hitam atau karena status, jabatan

\footnotetext{
${ }^{17} \mathrm{Hsu}$, Single at the Crossroads, 44

${ }^{18}$ Gary R, Collins, ed. It's Ok to be Single, (Waco: Word Publishers, 1976), 25.

19 Elva McAllaster, Free to be Single, (New York: Christian Herald Books, 1979), 81.
} 
atau apapun juga. Melainkan identitas orang percaya adalah umat perjanjian Allah. Karena itu gereja harus bertobat dari cara pandangnya yang eksklusif yang hanya ditujukan kepada pernikahan semata dan mengabaikan kelajangan. Dalam hal pelayanan dalam gereja, maka persoalannya bukan soal menikah atau lajang melainkan soal dipanggil dan dikaruniai oleh Roh Kudus untuk melayani umat apakah berasal dari latar belakang yang sama atau yang tidak sama dengan pelayan tersebut entah itu dari sisi ras, gender, status pernikahan dan lain-lain.

Gereja perlu mengembangkan sikap transformatif lebih lanjut, di antaranya menghormati para lajang dan mendukung kebutuhan mereka agar para lajang dapat berperan secara maksimal dalam membangun komunitas beriman. ${ }^{20}$ Para lajang terus bertarung dalam ketidaknyamanan, kesepian dan frustrasi dalam cara yang unik, bahkan ini terjadi dalam gereja. Creswell mencatat dengan mengutip Clarkson bahwa banyak para lajang memiliki kedukaan tersendiri dan masalah tersendiri karena tidak dipahami oleh dunia di mana dia berada. Banyak dari para lajang mengalami kesendirian yang luar biasa dan menjadi bahan perhatian yang berlebihan di gereja sehingga kebutuhan mereka akan kasih dan persekutuan secara luas diabaikan. Bahkan lajang yang tidak pernah menikah memiliki intensitas persoalan semakin meningkat karena mengalami rasa sakit akibat keterasingan, kesepian dan marginalisasi yang disebabkan karena mereka dianggap mengikuti norma yang tidak wajar dalam jalur penikahan. Akibatnya bukan hanya gereja, tetapi juga masyarakat tidak mengetahui bagaimana bersikap dengan mereka. ${ }^{21}$

Seharusnya mereka tidak hidup dalam realitas demikian, karena memang tidak baik manusia hidup seorang diri saja. Manusia diciptakan Allah ada dalam persekutuan satu dengan yang lain. Karena itu gereja dapat menyediakan suatu kelompok lajang, yang di dalamnya mereka menemukan suatu persekutuan erat untuk membangun kehidupan bersama.

Memang harus disadari bahwa pelayanan kepada para lajang dapat menjadi suatu kesulitan tersendiri berkaitan dengan

\footnotetext{
${ }^{20}$ Collins, ed. It's Ok to be Single, 27.

${ }^{21}$ Sylvia Creswell, Singleness and the Church, diakses dari file:///G:/Singleness\%20and\%20the\%20Church\%20Sylvia\%20Cresswell.pdf, tanggal 15 Februari 2015
} 
kebutuhan yang beraneka ragam dari para lajang. Meskipun demikian gereja tidak dapat mengabaikan kebutuhan tersebut dan kebutuhan-kebutuhan tersebut tidak dapat dilayani dalam satu metode dan hal ini tidak berarti dibukanya komisi lajang. Yang utama di sini adalah apakah gereja melibatkan para lajang dalam pelayanan mereka dan bukan hanya pelayanan yang berorientasi kepada keluarga. Karena itu pelayanan kepada para lajang ini tidak berarti memisahkan mereka keluar dari tubuh Kristus, namun menolong mereka bertumbuh dalam perjalanan iman mereka dalam suatu cara yang memperkaya keseluruhan dari tubuh Kristus. ${ }^{22}$

Pelayanan kepada para lajang dengan semangat penginjilan yang tinggi juga akan bermanfaat bagi gereja dan komunitas lokal. Gereja di kota-kota besar harus berpikir dalam cara yang kreatif untuk memengaruhi masyarakat yang sangat individualistis dalam suatu kerangka kehidupan unit keluarga yang non tradisional. Suatu pelayanan kepada para lajang yang sehat dapat memberikan suatu tawaran kepada para lajang, yang merasa terasing dalam suatu masyarakat yang berorientasi kepada keluarga, suatu tempat yang menyenangkan di mana di dalamnya para lajang diterima dan dihargai.

\section{MERAYAKAN STATUS KELAJANGAN}

Secara umum, sebagaimana Grenz mengatakan di atas maka dalam hidup lajang pun ada suatu nilai yang patut dirayakan. Eklund mencatat beberapa hal di sini, yaitu: hospitalitas di mana mereka dapat melakukan secara leluasa praktek keramahtamahan ini. Para lajang memiliki kesempatan yang luas untuk menumbuhkan keramah-tamahan ini di luar ikatan dari keluarga yang merupakan suatu perwujudan kesaksian dari persaudaraan yang dibangun dalam Kristus.

Yount mengajak para lajang untuk merayakan kehidupan mereka dengan manfaat besar yang mereka dapat raih di dalam hidup. Yount mengatakan,

\footnotetext{
${ }^{22}$ Kris Swiatocho, Why Doesn't My Church Have a Singles Ministry? Diakses dari http://www.crosswalk.com/church/pastors-or-leadership/why-doesn-t-my-churchhave-a-singles-ministry.html, tanggal 15 Februari 2015.
} 
For starters, the single life awards you more freedom and independence.You need answer to no one but yourself, avoiding reluctant compromise and emotional conflict. You will have to cook and clean for yourself, of course, but you alone will choose the menu according to your taste and you can set your own standards. You can enjoy the leisure to explore new interests that will make you a more interesting person to others and a better friend. It is not selfish to do things for yourself that you are free to do. What is selfish is to limit someone else's freedom by tying them to you when you cannot reciprocate fully. Happily, the single life guarantees you greater control over your time, which you may elect to spend helping others less fortunate than yourself.Alternatively, you can spend time advancing your career, going back to school, or caring for friends. ${ }^{23}$

Dorongan Yount untuk para lajang di atas membuka suatu kesempatan seluas-luasnya bagi para lajang di dalam mengembangkan diri mereka secara lebih positif. Namun di sisi lain ada banyak juga para lajang yang bergumul dengan kerinduan mereka akan keintiman seksual, komitmen dalam pernikahan atau memiliki anak. Namun kelajangan karena keputusan pengabdian kudus dalam kerajaan Allah maka menuntut para lajang harus belajar mendisiplinkan dirinya dalam cara yang unik untuk mengatasi keinginan tersebut. Cara kristiani yang dapat dilakukan adalah dengan memfokuskan diri dalam suatu latihan untuk masuk kepada keinginan Allah dan ke dalam suatu keterlibatan diri dalam pelayanan yang menjadi berkat bagi banyak orang.

Bagi para lajang yang memang tidak memiliki anak secara biologis, maka kehidupan mereka menggambarkan suatu kesaksian kristen tertentu kepada gereja yang dilahirkan baru dan masuk ke dalam keanggotaan gereja melalui baptisan. Keluarga mereka adalah anggota kerajaan Allah meskipun mereka tidak melahirkan anak. Dalam suatu budaya di mana muncul suatu ungkapan bahwa anak adalah masa depan dari dunia kita, maka para lajang tidak memiliki hal ini dalam hidup mereka. Namun kondisi ini justru mendorong para lajang untuk berdiri di atas menara iman bahwa suatu hari nanti akan ada kebangkitan, dan

${ }^{23}$ David Yount, Celebrating Single Life: Keys to Successful Living on Your Own (Post Road West, Westport, CT: Praeger Publishers, 2009), 5. 
jikalau mereka dikenang maka keluarga dari gereja itulah yang mengenang mereka.

Dalam hal ini, maka para lajang tidak usah sungkan untuk meminta bantuan, karena kecenderungan para lajang adalah sangat mandiri. Mereka harus belajar melayani satu dengan yang lain dengan penuh kasih tanpa mengeluh, dan karena itu menjadikan tubuh Kristus itu saling berkait dalam hidup gereja dan akhirnya gereja dapat memenuhi misinya. (Gal. 5;13; I Pet 4:9). Para lajang dalam hal ini masuk dan terlibat di dalamnya melampaui keluarga inti, suku, tingkat sosial, gender dan kelompok-kelompok tertentu (Gal.3:28) di dalam membuat ketersediaannya hidup mereka kepada sesama.

\section{LAJANG DALAM PELAYANAN MEREKA}

Pelayanan dan kelajangan keduanya dapat menjadi berkat, namun waspadalah juga karena sebagai pelayan yang lajang, ada beberapa karakteristik pelayanan dan kelajangan yang jika digabungkan dapat menjadi tanah yang subur untuk mendisiplinkan keinginan-keinginan yang jikalau tidak ditangani akan memperbudak hati mereka dan menuntun kepada akibat yang berbahaya dalam kehidupan dan pelayanan.

Seorang pribadi yang sudah dipisahkan oleh Allah untuk melayani umat-Nya adalah seorang pribadi yang dipanggil untuk suatu tugas yang mulia. Tugas ini hanya dapat dipenuhi dengan setia dan sebagai suatu pelayanan publik yang dilakukan maka hal ini tidak dapat dipisahkan dengan kehidupan privatnya karena pelayanan publik ini merupakan suatu aliran bagian dari kehidupan privat. Pelayanan privat di sini adalah kehidupan yang dihidupi di tempat di mana orang lain tidak melihat, yaitu suatu kehidupan di antara pelayan itu sendiri dan Allah. Ini adalah tempat di dalam kehidupan di mana pelayanan yang berhasil itu akan dimenangkan atau justru mengalami kehilangan.

Seorang pelayanan yang dipisahkan bagi Allah ditentukan di tempat ini. Dalam kaitan ini, seorang pelayan yang adalah lajang dan tantangan dari kelajangan itu bertemu. Dalam situasi ini, beban, keterasingan, pencobaan, dan kesulitan-kesulitan yang lain sering kali meningkat dalam intensitasnya. Dengan memahami kesulitan ini maka akan menolong para lajang dalam pelayanan 
mereka mengatasi hal ini dan akibatnya mereka dapat melayani umat Allah dengan baik.

Satu keuntungan dari para lajang dalam pelayanan mereka adalah bahwa mereka dapat berkonsentrasi lebih kepada pelayanan mereka sebagai anggota dari tubuh Kristus, mereka juga diperlengkapi dengan karunia untuk melayani tubuh Kristus. Banyaknya preferensi dari gereja untuk mengambil pelayanan para lajang demi penghematan memang menjadi suatu tantangan bagi para pelayan yang menikah hari ini. Namun alasan efisiensi ini juga terkadang mengabaikan kesensitifan terhadap pelayanan bagi para lajang.

Karena para lajang tidak memiliki pasangan tidak berarti gereja dapat menuntut yang berlebihan kepada mereka karena secara pribadi juga mereka membutuhkan ruang privasi diri. ${ }^{24}$ Memang tuntutan dari jemaat terhadap pelayan yang lajang sering kali berbeda dari tuntutan yang diberikan kepada pelayan yang sudah menikah. Dalam hal ini jemaat sering kali berharap bahwa para lajang ini dapat melakukan banyak hal. Mereka berasumsi bahwa pendeta lajang ini memiliki kemampuan dan ketersediaan untuk datang dan melakukan banyak pelayanan. Namun di sisi lain, para lajang membutuhkan waktu untuk membangun hidupnya secara pribadi.

Seorang lajang dapat dipakai Allah secara luar biasa untuk memberikan inspirasi bagi banyak orang, di antaranya John Stott yang dikenal pada hari ini. Kelajangan itu sendiri bukanlah suatu masalah, namun gereja perlu terus mendorong dan merangkul para lajang ini dan pelayanan yang mereka lakukan. Bahkan kita perlu merayakan lebih efektif lagi karunia kelajangan ini bagi umat Allah dalam pelayanan yang sudah mereka lakukan dalam segala usia. Grenz menasihati gereja dan para lajang demikian,

In the Church today we need single men and women of profound spiritual depth who, out of the resources of their own interior life with the Lord, live as other Christs in the

${ }^{24}$ Carolyn A. Crawford, "Ministry From A Single Perspective: Assets And Liabilities," The Journal of Pastoral Care. 42:2 (Summer 1988): 117-123 
world and radiate that power to a population hungry for true Christian formation. Singles do have a mission in life to fulfill, a special yet foundational task fashioned for them by God. No matter how narrow or expansive their circumstances, no matter how limited or gifted their ability, they can and must radiate a meaning no other person can give to the world in present and future times. And this meaning, this task, is to reflect the expansive love of the Redeemer, who wills that all share in the eschatological community of male and female that even now may be found in proleptic fashion in the church. Single Christians, therefore, who because of their abstinence from genital sexual expression are often " in touch "with their affective sexuality, have a unique ministry of love to offer in service to the Lord within the fellowship of the community of Christ. ${ }^{25}$

Merayakan pelayanan yang dilakukan para lajang di dalam gereja menjadi hal yang sangat penting. Menyadari kelebihan dan kekurangan dari kelajangan ini, maka agar supaya pelayanan dari para lajang ini menjadi efektif, maka ada beberapa wilayah yang harus diperhatikan sebagaimana disarankan oleh Alex Harrison. ${ }^{26}$

Saran yang diberikan adalah agar para lajang mengingat mengapa mereka dipanggil oleh Allah. Panggilan ini untuk melakukan secara utama pekerjaan Allah untuk bertumbuh dan berkembang secara rohani. Para lajang memang memainkan peran penting dalam gereja Allah, dan sekaligus menjadi aset penting bagi gereja dalam pengembangan pelayanan. Dalam hal ini, maka para lajang harus memastikan mereka terlibat penuh dalam persekutuan dan semua aktivitas pelayanan yang mungkin dilakukan tanpa harus mengorbankan kebutuhan privasi diri.

Para lajang juga harus menghormati sesama lajang yang lain karena memang masing-masing memiliki kepribadian yang berbeda. Dalam hal ini, maka mereka harus memperhatikan cara mereka berbicara dan memberikan pendapat tentang sesama mereka, serta diharapkan mereka mengembangkan semangat

\footnotetext{
${ }^{25}$ Grenz, Sexual Ethics, 196

${ }^{26}$ Alex Harrison, How to Serve God as a Single: Singles do play a major role in God's Church, diakses dari https://www.pcog.org/articles/248/how-to-serve-godas-a-single, tanggal 15 Februari 2015.
} 
positif satu dengan yang, tetap percaya diri dan mempertahankan kehidupan damai sejahtera satu dengan yang lain, khususnya dalam relasi dan persahabatan satu dengan yang lain (band. Kol. 3:12-15). Yang pantas juga untuk dipikirkan dalam merayakan pelayanan ini adalah agar para lajang menghargai keluarga rohani mereka. Ada suatu upah yang besar dalam keluarga rohani ini (band. Mat. 19:29). Carilah kesempatan untuk melayani sesama dan layanilah mereka dalam kapasitas diri sebagai seorang lajang.

Dalam konteks pelayanan ini, maka para lajang harus tetap menjaga standar hidup secara moral dan rohani dengan benar, baik dalam percakapan, berbusana dan dalam tindakan. Dalam hal ini, maka izinkan Allah selalu berkarya dan mempersiapkan diri anda untuk tunduk kepada kehendak-Nya. Jikalau para lajang merasakan suatu sindrom kesepian, maka benamkan diri anda ke dalam pekerjaan Allah. Menjadi sepi bisa jadi karena sering kali para lajang hanya memfokuskan terlalu banyak pada diri sendiri. Hindari hal ini dengan masuk ke dalam pekerjaan Allah yang lebih, yang sudah dipercayakan kepada anda.

Jadilah puas karena kelajangan ini karena menjadi lajang adalah suatu batu lompatan, suatu seri pengalaman dalam perarakan kehidupan iman. Belajarlah hidup sampai pada tahap penuh dalam kelajangan itu dan jangan membandingkan diri dengan orang lain (II Kor. 10;12). Allah sedang mengembangkan karakter penting dalam kelajangan itu juga, baik secara fisik maupun secara rohani. Allah sudah memanggil para lajang dalam pelayanan-Nya, dan apapun keadaan para lajang ini, mereka harus berserah kepada tujuan Allah yang tertinggi dan besar. Para lajang adalah penting juga di hadapan Allah. Jadi jangan abaikan pelayanan mereka. 


\section{KESIMPULAN}

Kehadiran para lajang dalam gereja dan pelayanan hari ini secara jumlah dapat meningkat, khususnya di kota-kota besar, dapat menjadi suatu tantangan tersendiri dalam pelayanan gereja. Gereja terpanggil dalam cara-cara yang lebih kreatif untuk melayani mereka dan mengembangkan suatu pelayanan gereja yang bersifat inklusif dan bukan hanya pelayanan yang bersifat eksklusif yang hanya berorientasi kepada keluarga semata.

Perubahan sikap gereja yang transformatif ini dilandasi oleh cara dan sikap Yesus yang berimbang kepada realitas para lajang dan mereka yang sudah menikah, yang sama-sama nyata dalam komunitas umat Allah yang diselamatkan dan yang melayani Dia. Para lajang yang melayani umat Allah hendaknya mendapatkan sikap yang berimbang dari gereja sebagaimana mereka memperlakukan pelayan yang sudah menikah. Sikap berimbang ini penting sebagai wujud ketaatan mereka kepada Yesus Kristus yang sudah membangun tataran komunitas yang baru dalam kerajaan-Nya. Gereja Yesus Kristus seharusnya memberikan teladan bagaimana seharusnya suatu komunitas itu hidup dan saling melayani secara benar di dalamnya.

Di sisi lain, hendaknya para lajang merayakan kehidupan yang benar dalam komunitas umat beriman dan mereka yang terpanggil dalam melayani gereja mengerjakan itu dengan suatu semangat panggilan kehidupan yang tinggi seperti yang sudah diberikan teladan oleh Kristus, Paulus dan para lajang dalam sejarah yang sudah memberikan hidup mereka untuk melayani Allah melalui Gereja-Nya. 


\section{KEPUSTAKAAN}

Almlie, Mark. Are We Afraid of Single Pastors? Diakses dari http://www.christianitytoday.com/parse/2011/january/are-weafraid-of-single-pastors.html, tanggal 15 Februari 2015.

Byrne, Anne. "Single Women In Ireland," Women on Their Own: Interdisciplinary Perspective on Being Single, ed by Rudolf M.bell and Virginia Yans. London: Rutgers University Press, 2008.

Collins, Gary R, ed. It's Ok to be Single. Waco: Word Publishers, 1976.

Crawford, Carolyn A. "Ministry From A Single Perspective: Assets And Liabilities," The Journal of Pastoral Care. 42:2 (Summer 1988).

Creswell, Sylvia, Singleness and the Church, diakses dari file:///G:/Singleness\%20and\%20the\%20Church\%20Sylvia\%20Cre sswell.pdf, tanggal 15 Februari 2015

Eklund, Rebekah. A Theology of Singleness, diakses dari www.bemidjicovenant.com/filerequest/2989.pdf, tanggal 13 Februari 2013.

Ervine, Clyde. Single in the Church: Eunuchs in the Kingdom.

Diakses dari www.biblicalstudies.org.uk/pdf/churchman/119-03_217.pdf, tanggal 13 Februari 2015.

G, Dominique, Chinese Women's Life. Diakses dari

http://chinesewomenslife.blogspot.com/2010/10/traditionalrole-of-women-in-china.html, tanggal 13 Februari 2015

Grenz, Stanley J. Sexual Ethics: An Evangelical Perspective. Louisville: John Knox Press, 1990.

Harrison, Alex. How to Serve God as a Single: Singles do play a major role in God's Church. Diakses dari 
https://www.pcog.org/articles/248/how-to-serve-god-as-asingle, tanggal 15 Februari 2015.

Hsu, Albert, Singles at the Crossroads: A Fresh Perspective on Christian Singleness. Downers Grove, IVP Books, 1997.

Kerr, Hugh Thomson, A Compend of Luther's Theology: Martin Luther on Marriage and Divorce, diakses dari

http://www.teleiosministries.com/pdfs/Marriage_Divorce/marti n_luther_on_marriage_and_divorce.pdf, tanggal 16 Februari 2015.

McAllaster, Elva. Free to be Single. New York: Christian Herald Books, 1979.

Puspitasari, Krisetiawati. "Lajang Bukan yang Terbuang, Bahana, Agustus 2009. Diakses dari http://www.ebahana.com/warta1156-LAJANG-BUKAN-YANG-TERBUANG.html, tanggal 13 Februari 2015.

Lyon, William. A Pew for One, Please: The Church and the Single Person. New York: Cross Road Book, 1977.

Metcalf, Charlotte. Stigmatised for being single: More women are choosing to live alone but they're becoming irritated at being pitied and patronised by their married friends. Diakses dari http://www.dailymail.co.uk/femail/article-

2070914/Stigmatised-single-More-women-choosing-livealone.html, tgl 13 Februari 2015.

Stott, John. Singleness. Diakses dari

http://www.christianitytoday.com/ct/2011/augustwebonly/johnstottsingleness.html tanggal 13 Februari 2015.

Swiatocho, Kris, Why Doesn't My Church Have a Singles Ministry? Diakses dari http://www.crosswalk.com/church/pastors-orleadership/why-doesn-t-my-church-have-a-singlesministry.html, tanggal 15 Februari 2015.

Trull, Joe E. \& James E. Carter. Ministerial Ethics. Grand Rapids: Baker Book, 2004. 
Yount, David. Celebrating Single Life: Keys to Successful Living on Your Own. Post Road West, Westport, CT: Praeger Publishers, 2009. 